\title{
Pleuropulmonary complications related to pulmonary instillation of activated charcoal
}

\author{
Complicações pleuropulmonares relacionadas à \\ instilação pulmonar de carvão ativado
}

\author{
Luiz Felipe Nobre, Edson Marchiori, Daniel Yared Forte, Gláucia Zanetti
}

\section{To the Editor:}

Recently, Bairral et al. ${ }^{(1)}$ described the interesting case of a 20-year-old female patient who attempted suicide by ingesting lead shot. She was treated with atropine and received $50 \mathrm{~g}$ of activated charcoal (AC) diluted in $400 \mathrm{~mL}$ of mannitol administered through a gastric tube. A few hours later, the patient vomited, as well as experiencing a decreased level of consciousness and agonal respiration. At bronchoscopy, blackish material mixed with food debris was obtained, characterizing the occurrence of aspiration of the material. Imaging studies revealed bilateral alveolar opacities.

We would like to report our experience of a case of attempted suicide in which the pulmonary and pleural complications were due not to aspiration, but to direct instillation of $A C$ into the airways. The patient was a 23-year-old female who was admitted to the hospital approximately one hour and a half after the ingestion of $200 \mathrm{mg}$ of paroxetine. Upon her arrival, she was in a coma and underwent gastric lavage with a solution of $1.5 \mathrm{~L}$ of AC. The patient immediately developed dry cough and dyspnea. A chest X-ray showed right pleural effusion, and, during thoracentesis, there was discharge of black fluid, identified as AC (Figure 1). A CT scan showed pleural effusion and consolidation in the right lower lobe, both of which exhibited high density (attenuation values of approximately $130 \mathrm{HU}$ ), as well as pneumothorax (Figure 2). These findings raised the suspicion of direct instillation of $A C$ into the lungs due to placement of the nasogastric tube within the patient's airway. At bronchoscopy, there was discharge of black material from the right lower lobe. An air leak was noted from the chest tube, suggesting bronchopleural fistula. The patient underwent thoracoscopy and pleural lavage. Fifteen days later, the fistula closed, and the patient was discharged from the hospital.
Some of the data on this case have been reported in a previous publication. ${ }^{(2)}$

Most of the complications related to treatment with $A C$ result from aspiration of gastric content, as has been reported by Bairral et al., ${ }^{(1)}$ rather than from direct aspiration of AC. Occasionally, the nasogastric tube can be mistakenly inserted into the trachea, and there can occur direct administration of AC into the airways. Another complication related to direct instillation of charcoal into the airways is pleural involvement. Findings of pleural effusion, presence of charcoal in the collected fluid, and pneumothorax associated with bronchopleural fistula are probably secondary to instillation of a large amount of AC solution into the distal airways. ${ }^{(3)}$ Pleural rupture caused by the nasogastric tube, rupture of a subpleural bulla after aspiration (with consequent development of a bronchopleural fistula), and perforation of the esophagus, with formation of an esophagopleural fistula, are possible mechanisms for pleural involvement. ${ }^{(4)}$

The incidence of inadvertent insertion of the nasogastric tube into the trachea and the distal airways ranges from $0.3 \%$ to $15 \% .{ }^{(5)}$ Physical examination is often not a good predictor of incorrect positioning of the tube, especially in unconscious patients. In general, the positioning of the tube is initially assessed by fluid aspiration or by air insufflation and auscultation of the abdomen. These maneuvers can provide falsepositive results. ${ }^{(6)}$ The position of the tube should be verified radiographically before the administration of AC. $^{(3)}$

In conclusion, in patients treated with AC, a CT finding of high-density material in the lung parenchyma or the pleural cavity is strongly suggestive of accidental instillation of the product into the airways. 

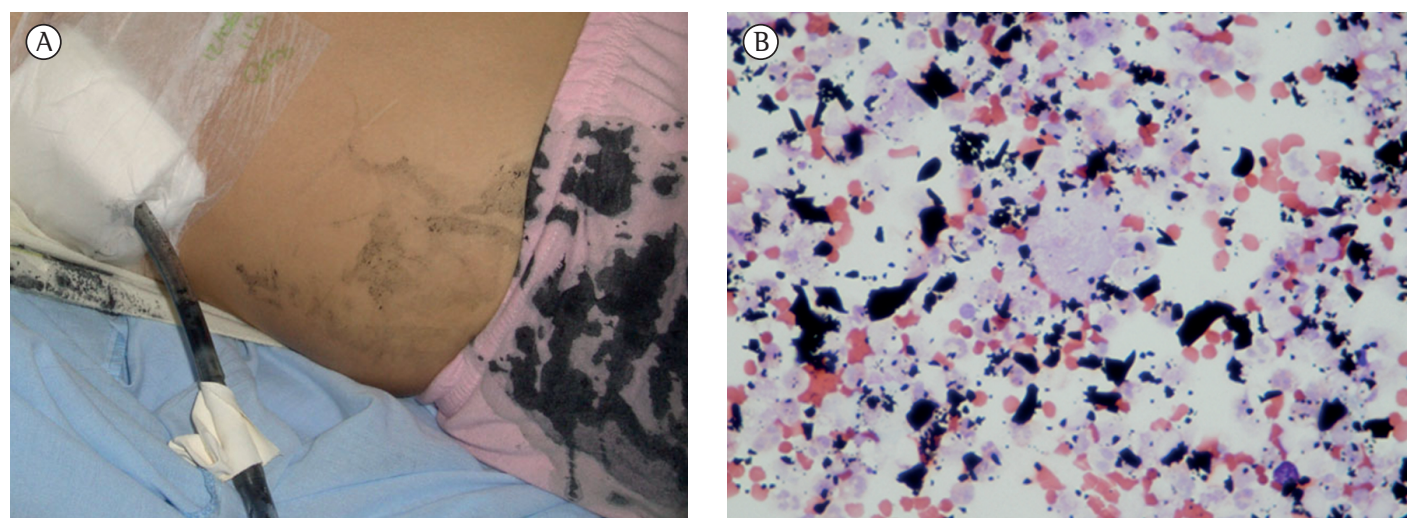

Figure 1 - In A, photograph of the patient, which was taken after placement of the chest tube, showing the presence of blackish fluid (discharged during the procedure) in the tube. In B, photomicrograph of the pleural fluid showing the presence of charcoal particles (HEtE; magnification, $\times 400$ ).
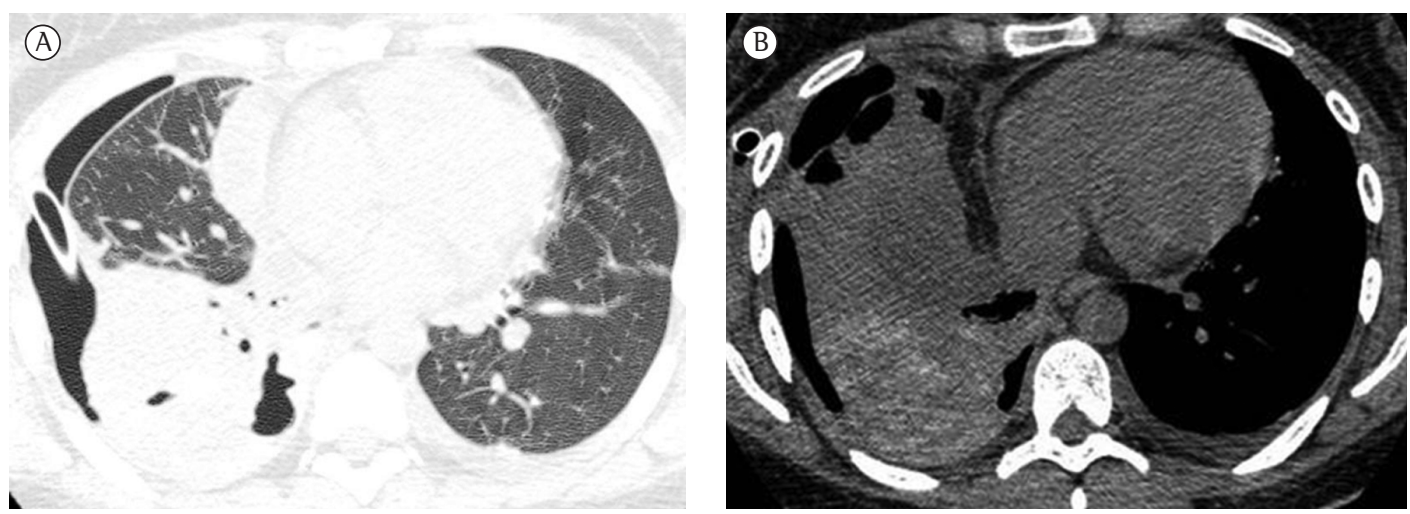

Figure 2 - Chest CT scan. In A, slice on lung window showing right hydropneumothorax, which had been drained, as well as parenchymal consolidation. In B, slice on mediastinal window showing high-attenuation areas within the consolidation, measuring approximately $130 \mathrm{HU}$.

\section{Luiz Felipe Nobre Professor of Radiology, Federal University of Santa Catarina, Florianópolis, Brazil}

\section{Edson Marchiori}

Associate Professor of Radiology, Federal University of Rio de Janeiro, Rio de Janeiro, Brazil

\section{Daniel Yared Forte}

Former Resident in Pulmonology, Federal University of Santa Catarina, Florianópolis, Brazil

\section{Gláucia Zanetti}

Professor of Clinical Medicine, Petrópolis School of Medicine, Petrópolis, Brazil

\section{References}

1. Bairral BQ, Saito M, Morrone N. Activated charcoal bronchial aspiration. J Bras Pneumol. 2012;38(4):533-4. http://dx.doi.org/10.1590/S1806-37132012000400018 PMid:22964940

2. Nobre LF, Marchiori E, Carrão ÂD, Zanetti G, Mano CM. Pulmonary instillation of activated charcoal: early findings on computed tomography. Ann Thorac Surg. 2011;91(2):642-3; author reply 643. http://dx.doi. org/10.1016/j.athoracsur.2010.06.064 PMid:21256344

3. Seder DB, Christman RA, Quinn MO, Knauft ME. A 45-year-old man with a lung mass and history of charcoal aspiration. Respir Care. 2006;51(11):1251-4. PMid:17067407

4. Sabga E, Dick A, Lertzman M, Tenenbein M. Direct administration of charcoal into the lung and pleural cavity. Ann Emerg Med. 1997;30(5):695-7. http://dx.doi. org/10.1016/S0196-0644(97)70090-8

5. Boyes RJ, Kruse JA. Nasogastric and nasoenteric intubation. Crit Care Clin. 1992;8(4):865-78. PMid:1393755

6. Thomas B, Cummin D, Falcone RE. Accidental pneumothorax from a nasogastric tube. N Engl J Med. 1996;335(17):1325. http://dx.doi.org/10.1056/ NEJM199610243351717 PMid:8992337 